DOI: 10.20472/BM.2019.7.2.004

\title{
CUSTOMS UNION EFFECT IN INTERNATIONAL TRADE: TURKISH CASE
}

\section{ERKAN ERDIL, YILMAZ AKDI}

\begin{abstract}
:
This study is an attempt to analyze Customs Union effect in terms of co-integration and periodicity in international trade for Turkey. The most significant contribution of the paper is its use of improved methods to detect periodicity in international trade data. Customs Union (CU) with EU has shown to have significant impacts in EU-Turkey trade relations yet no other study measure the impact of CU in terms of periodicity. In order to search for hidden periodicities in the data, periodograms and periodogram based unit root tests having various strengths as compared to standard methods. The findings show that CU has an impact in EU-Turkey trade relations with regard to periodicity. The study has also policy contributions for similar free trade agreements such as modernized customs union, post-Brexit talks, and new EEA agreements.
\end{abstract}

\section{Keywords:}

International trade; Customs union; Brexit, Co-integration; periodicity

JEL Classification: F10, F13, C10

\section{Authors:}

ERKAN ERDIL, Department of Economics, Turkey, Email: erdil@metu.edu.tr YILMAZ AKDI, Department of Statistics, Faculty of Science Ankara University, Turkey, Email: akdi@ankara.edu.tr

\section{Citation:}

ERKAN ERDIL, YILMAZ AKDI (2019). Customs Union Effect in International Trade: Turkish Case.

International Journal of Business and Management, Vol. VII(2), pp. 43-58., 10.20472/BM.2019.7.2.004 


\section{Introduction}

The economic impacts of international trade are always top in the global agenda as evident from the recent trade wars among countries and country blocks. The competitiveness pressures make the international trade a significant economic driver at various levels, namely firm, sector, country, and supranational levels. Over the last decades the competitiveness rationale has been gaining ground in the $\mathrm{EU}$ and has become ever more important in an increasingly interrelated and global setting. It has given rise to increased coordination needs in the economic sphere. In 2010 the EU, driven by these concerns of international competitiveness, launched the Europe 2020 Strategy in order to tackle the (global) financial crisis and prepare the EU economy for the next decades. The EU is faced with a trilemma: reducing the public deficit, investing in 'going green', as well as preserving the welfare state and public services, which also has important repercussions for Turkey and the neighborhood. While Turkey, with its geographical position and geostrategic reach, provides access to regional markets and thereby contributes to enhancing smart, sustainable and inclusive growth, this trilemma is also related with some of the challenges that Turkey has to face, such as those noted in the Commission's Progress Reports. Turkey will have to be able to cope with competitive pressure and market forces within the Union in the medium term, provided that it accelerates the implementation of comprehensive structural reforms. Finally, the uniqueness of Turkey is the fact that she is the only largest economy having an extensive CU agreement with EU.

Another hot issue in the agenda concerning free trade agreements is recent developments inside EU, United Kingdom exit from EU (Brexit). The studies on impact of free trade agreements basically provide input for evidence-based policy making for the parties of such agreements. In fact the CU is more than a free trade agreement and brought larger benefits especially for Turkey by supplying an anchor on Turley's applied tariffs for industrial products and negated the need for rules of origin on bilateral trade (World Bank, 2014). Regarding the talks between EU and Turkey for the modernization of existing CU covering the agriculture and services, Turkey would particularly obtain further benefits especially in service sector. As noted by Felbermayr, et al. (2016) such a modernization is estimated to have $2.5 \%$ additional gain to Turkey's GDP. Furthermore, the modernization of $\mathrm{CU}$ is expected to provide welfare gains for EU. On the contrary, based on a simulation model, to roll back from CU to an ordinary free trade agreement will result a fall in Turkey's GDP by $0.81 \%$ (Felbermayer, et al., 2016).

The EU has consistently been Turkey's largest trading partner. In this sense, the paper with a focus of trade between EU and Turkey, aims to contribute to the literature by providing evidence on the possibility of periodicity in trade. The paper will also search answers for the impact of the Customs Union in terms of periodicity. Two major forces act and react in the flows of goods and services, 
namely globalization and regionalization. In this context, Turkey presents an interesting case because of several reasons. Firstly, Turkey is one of the first countries that started to open her economy to free trade among the developing countries. In 1980, Turkey has changed its growth strategy from import substitution to export promotion. Since then, Turkey has shifted its trade pattern from exporting primary and agricultural products and importing manufactured goods to exporting manufacturing and intermediate goods. This structural change has changed the composition of exports and imports in Turkey. Secondly, Turkey has become member of Customs Union (CU) of EU in 31 December 1995 though it is not member to EU. This decision was a tendency towards major regionalization attempt. As evident from the literature, there seems to be structural change in Turkey's trade flows after CU (Bilici, et al., 2011 and Ekmen, 2012).

The study has two significant contributions to the literature. First, it provides a quite novel methodology to measure periodicity in international trade and in preferential trade agreements. Second, it provides policy implications on preferential trade agreements from the unique case of EUTurkey CU agreement and further exhibits evidence for the possible restructuring of new EU-UK trade relations after the Brexit. The paper is organized as follows. The next section will discuss the literature briefly, then data and methodology are presented in the third section. The Fourth section exhibits the empirical findings. Finally, we discuss the policy implications and general conclusions derived from the results.

\section{A Snapshot on the literature}

The analysis on the impacts of preferential trade agreements has a long-standing narrative in the literature after the post-war era. The attractiveness of the topic seemed to be lessened in 1970s, it has gained a momentum especially after the globalization chapter. The EU market is a significant target for the export activities of the developing world and free trade agreements is used as a leverage to overcome some structural problems in international trade. The possible impacts of trade activities and free trade agreements, therefore, attract researchers to focus on the issue in detail. As noted by Benedictis and Salvatici (2011:4), the literature on trade policies has developed through three channels, namely economic analysis of the GATT/WTO multilateral trade system; analysis of trade policy instruments in detail; ex ante analysis of trade policy. Benedictis and Salvatici (2011) further blames the existing literature to have little attention, until recent years, on ex post analysis based on observational studies and econometrics.

One of the most preferred approach is to use Gravity Model to clarify determining role of total trade flows. Gravity model is based on Newton's Gravity Law. Main argument of this model is that foreign trade is determined by demographic and economic factors. Gravity model is firstly used to explain 
trade flows between countries (Tinbergen, 1962 and Pöyhönen, 1963). Many researchers used different gravity models and they obtained similar results consistently for EU-Turkey trade relations, so it has become one of the widely used models to explain trade flows in the literature. There are many applications of gravity model concerning economic integration. For instance, Frankel (1997) used the model to explain determinants of inter and intra integration trade of EC, EU, EFTA, CUFTA, MERCOSUR and ASEAN. Soloaga and Winters (1999) conducted a similar study for EU, EFTA, NAFTA, MERCOSUR and ASEAN. Likewise, Kruger (1999) used the gravity model for NAFTA. Gravity model is also used to clarify determinants of Turkey's trade flows and reasons of changes in these flows. Antonucci and Manzocchi (2006) used gravity model to explain Turkey's trade flows during 19672001 period. Firstly, they demonstrated that the model explains Turkey's trade pattern statistically. Then, they used the model to explain whether EU has a special role concerning the commodity trade between Turkey and EU. In other words, they investigated whether the volume of foreign trade between Turkey and EU is greater than the model suggests. According to empirical results, CU has no significant role in Turkey's trade with EU. But, from the critical perspective, we think that time period of analysis is not appropriate to investigate effects of $\mathrm{CU}$, because time period of $\mathrm{CU}$ membership is limited with 5 years. Lejour and Mooij (2005) simulated economic effects of Turkey's full membership to EU. Firstly, they determined potential trade between Turkey and EU for 15 sectors by the gravity model. Then, they found the custom equivalence of trade barriers by comparing numbers of potential trade and actualized trade. They calibrated 2001 world data in order to simulate computable general equilibrium model and analyzed economic effects of Turkey's full membership to EU after removal of foreign trade barriers. This study demonstrated that Turkey's foreign trade will be positively affected by Turkey's affiliation to EU. Likewise, they proposed that foreign trade of EU-15 and EU-25 countries will be affected positively by this affiliation although it will be marginal. According to Charilaos (2017), for the total volume of trade and the trade in the five different sectors between Turkey and its trading partners show that the standard gravity model is a conditional predictor of bilateral trade flows between Turkey and its trading partners. There are few differences in trading patterns between the different sectors. Liorgovas and Skandalis (2012) investigates the impact of trade openness on FDI flows for developing countries including Turkey for the period 19902008 by using panel data estimation techniques. It is found that trade openness creates positive impacts for the developing countries attractiveness for FDI (Liorgovas and Skandilis, 2012: 329). However, though considering the spatial impacts, these models generally ignores possible periodicity and related repercussions on the flows of trade. Moreover, the existing models generally ignores or partially considers the random forces in action. The current paper unearths the incidence of periodicity and, then, discusses the implications of the periodicity in EU-Turkey axis. 


\section{Data and Methodology}

The international trade data in US dollars is monthly for the period 1980:01-2017:12 and collected by Turkish Statistical Institute (TÜIK). The analysis search for periodicity for three time periods for Turkish case, the whole data set and in order to treat the impacts of Customs Union 1980:01-1995:12 and 1996:01-2017:12. The stationarity of each period will be tested by Augmented Dickey Fuller (ADF) tests (Dickey and Fuller, 1979) and periodograms. Moreover, again for three time periods, both for exports and imports the cointegration relation will be investigated by Engle-Granger procedure and periodograms.

Periodograms are generally employed to investigate the hidden periodicities in time series. Furthermore, they can also be used to test stationarity of time series as well as to obtain cointegration relation for multivariate time series and to test co-integration in time series. In the following, these methods will be explained shortly.

\subsection{Stationarity}

Periodograms are calculated by a trigonometric transformation for a given time series data. Therefore, we consider the following trigonometric regression model given below (1):

$$
Y_{t}=\mu+A \cos \left(w_{k} t\right)+B \sin \left(w_{k} t\right)+e_{t}, t=1,2, \ldots, n .
$$

Here, $w_{k}=2 \pi k / n$ which are known to be Fourier frequencies. According to this model, the OLS estimators of the parameters $\mu, A$ and $B$ are calculated

$$
\hat{\mu}=\bar{Y}_{n}, \quad a_{k}=\frac{2}{n} \sum_{t=1}^{n}\left(Y_{t}-\bar{Y}_{n}\right) \cos \left(w_{k} t\right), \quad b_{k}=\frac{2}{n} \sum_{t=1}^{n}\left(Y_{t}-\bar{Y}_{n}\right) \sin \left(w_{k} t\right) .
$$

The OLS estimators $a_{k}$ and $b_{k}$ are known to be Fourier coefficients. Using these Fourier coefficient, the periodogram ordinate at the frequency $w_{k}$ is defined by

$$
I_{n}\left(w_{k}\right)=\frac{n}{2}\left(a_{k}^{2}+b_{k}^{2}\right) .
$$

From the properties of the trigonometric functions it is easy to obtain

$$
\sum_{t=1}^{n} \cos \left(w_{k} t\right)=\sum_{t=1}^{n} \sin \left(w_{k} t\right)=0
$$

which implies that Fourier coefficients are invariant with respect to the mean and therefore the periodogram ordinates are also invariant with respect to the mean.

Let $f\left(w_{k}\right)$ be the spectral density function and $I_{n}\left(w_{k}\right)$ be the periodogram ordinate of a stationary time series. Then, as $n \rightarrow \infty$

$$
I_{n}\left(w_{k}\right) / f\left(w_{k}\right) \stackrel{D}{\longrightarrow} \chi_{2}^{2} .
$$


That is the normalized periodogram ordinate converge in distribution to a chi-square random variable with 2 degrees of freedom for each fixed $k$ (Fuller, 1996 and Wei, 2006).

If the time series is not stationary a test statistic

$$
T_{n}\left(w_{k}\right)=\frac{2\left(1-\cos \left(w_{k}\right)\right.}{\hat{\sigma}_{n}^{2}} I_{n}\left(w_{k}\right)
$$

is defined. Under the null hypothesis that the series has a unit root, it is shown that (Akdi and Dickey, 1998)

$$
T_{n}\left(w_{k}\right) \stackrel{D}{\longrightarrow} Z_{1}^{2}+3 Z_{2}^{2} \quad, n \rightarrow \infty
$$

where $Z_{1}$ and $Z_{2}$ are independent random variables distributed with standard normal. Asymptotic distribution is valid for every $\mathrm{k}$ values and $k=1$ is generally used. The critical values of the distribution are provided by Akdi and Dickey (1998). Accordingly, the null hypothesis of unit root is rejected and series is stationary if $t_{n}\left(w_{k}\right)<c_{\alpha}$, where $\alpha$ stands for the level of significance, $c_{\alpha}$ for the critical value, and $t_{n}\left(w_{k}\right)$ for the value of statistics calculated for equation (5). The properties of unit rot tests based on periodograms are listed below:

i) Periodograms are invariant with respect to mean because of the properties of trigonometric functions. Therefore, the distribution of $T_{n}\left(w_{k}\right)$ statistics are invariant with respect to mean.

ii) The periodograms can be calculated without any model assumption. Thus, the periodograms are also model-invariant. Consequently, the technique do not need any parameter estimates except the variance of error terms.

iii) If there exists a periodic component in the series, it is more meaningful to test the stationarity of the series since periodograms are calculated with trigonometric transformation of series.

iv) The critical values of test statistics do not depend on the number of observations in the sample. Hence, the technique is more efficient for especially small samples.

v) The asymptotic distribution of test statistics is also valid for time series with seasonal unit roots, thus, the technique can also be used to test seasonal unit roots.

vi) If series are stationary with the spectral density function of $f\left(w_{k}\right)$, the distribution of $I_{n}\left(w_{k}\right) / f\left(w_{k}\right)$ statistics is chi-square with 2 degrees of freedom (exponential with the expected value of 1) and therefore the analytical power function of test exists.

\subsection{Co-integration}

As both series are integrated at order one, we can write $S_{t}$ as it stands for a stationary time series and $U_{t}$ for time series with a unit root:

$$
X_{t}=a_{11} U_{t}+a_{12} S_{t} \quad Y_{t}=a_{21} U_{t}+a_{22} S_{t}
$$


Here, $S_{t}$ stands for a stationary time series and $U_{t}$ stands for a unit root time series. Since both series are linear functions of $U_{t}$, both series are non-stationary. However, we can write

$$
Y_{t}-\left(a_{21} / a_{11}\right) X_{t}=\left(a_{21} U_{t}+a_{22} S_{t}\right)-\left(a_{21} / a_{11}\right)\left(a_{11} U_{t}+a_{12} S_{t}\right)=\left(a_{22}-a_{12} a_{21} / a_{11}\right) S_{t}=c S_{t}
$$

and $Z_{t}=Y_{t}-\left(a_{21} / a_{11}\right) X_{t}$ is stationary. Therefore, in order to check whether the series $X_{t}$ and $Y_{t}$ are co-integrated, it is enough to check the differenced series is stationary or not. If the difference series is stationary, then even $\underset{\sim}{X}=\left(X_{t}, Y_{t}\right)^{\prime}$ series are non-stationary, as $\underset{\sim}{\beta}=\left(-\left(a_{21} / a_{11}\right), 1\right)^{\prime}, \underset{\sim}{\beta^{\prime}} \underset{\sim}{X_{t}}$ is stationary and cointegration vector is $\underset{\sim}{\beta}$. The ultimate aim here is to estimate vector $\underset{\sim}{\beta}$ and test whether $\underset{\sim}{X}$ is two-dimensional cointegrated.

As it is seen, the difference series look like a residual series from the regression of $Y_{t}$ on $X_{t}$. That is, if the residual series is stationary then these series are cointegrated (Engle and Granger, 1987). Consider the regression equation

$$
Y_{t}=\beta_{0}+\beta_{1} X_{t}+e_{t}, t=1,2, \ldots, n
$$

and the OLS estimator of $\beta_{1}$

$$
\hat{\beta}_{1, n}=\left[\sum_{t=1}^{n}\left(X_{t}-\bar{X}_{n}\right)^{2}\right]^{-1}\left[\sum_{t=1}^{n}\left(X_{t}-\bar{X}_{n}\right)\left(Y_{t}-\bar{Y}_{n}\right)\right]
$$

is consistent for $a_{21} / a_{11}$.

At the above discussion on Engle and Granger methodology, in searching for the cointegration relation between two series, we underlined that $a_{21} / a_{11}$ ratio should be estimated. This ratio can also be estimated by periodograms. Akdi (1995) and Akdi et al. (2006) were investigated the cointegration relation between consumer price index and wholesale price index with a method based on periodograms for the period 1987:01-2014:08.

As $y_{k}$ stands for the real part of the $\mathrm{k}^{\text {th }}$ frequency of cross-periodograms of $X_{t}$ and $Y_{t}$ and $x_{k}$ for the $\mathrm{k}^{\text {th }}$ frequency of periodograms of $X_{t}$ (or $Y_{t}$ ), the following spectral regression model is considered:

$$
y_{k}=\alpha+\beta x_{k}+\eta_{k}, k=1,2, \ldots,[n / 2] .
$$

Here $[n / 2]$ shows the integer part of $n / 2$. According to this regression model, the OLS estimator of $\beta$, namely $\hat{\beta}_{P, n}$, is consistent for the ratio of $a_{21} / a_{11}\left(\hat{\beta}_{P, n} \stackrel{P}{\longrightarrow} a_{21} / a_{11}, n \rightarrow \infty\right)$. In order to check whether the series $X_{t}$ and $Y_{t}$ are cointegreted it will be enough to check the difference series, $Z_{t}=Y_{t}-\hat{\beta}_{P, n} X_{t}$, is stationary or not. To check the stationarity of this series we calculate $Z_{t-1}$ and $\nabla Z_{t}$ and regress $\nabla Z_{t}$ on $Z_{t-1}$ (namely $\nabla Z_{t}=\alpha_{0}+\alpha_{1} Z_{t-1}+u_{t}, t=1,2, \ldots, n$ ) and test the null hypothesis of $H_{0}: \alpha_{1}=0$. To test this hypothesis we calculate the usual $t$ statistic $\left(\hat{\tau}_{a}=\hat{\alpha}_{1} / s\left(\hat{\alpha}_{1}\right)\right)$ 
and compare the critical values. The distribution of the usual test statistic is not standart $t$ distribution (as it is happen Engle-Granger method). The critical values of the test statistic $\left(\hat{\tau}_{a}\right)$ are given in Akdi (1995) and Akdi et al. (2006). If the null hypothesis is rejected then we conclude that the residual series $Z_{t}$ is stationary and therefore the series $X_{t}$ and $Y_{t}$ are cointegreted.

\subsection{Periodicities}

Periodograms are also used to search hidden periodicities in a stationary time series. Since the periodograms are calculated by a trigonometric transformations, we consider a harmonic regression equation given in (1). According to the model, if the null hypothesis $H_{0}: A=B=0$ is rejected then the series contains a periofic component. The hypothesis can be tested by the usual $F$ statistic. However, since the frequencies $w_{k}$ are unknown, the $F$ test may not be appopriate (Wei, 2006). In order to test this hypothesis, we consider the test statistic

$$
V_{i}=\frac{I_{n}\left(w_{(i)}\right)}{\sum_{k=1}^{[n / 2]} I_{n}\left(w_{k}\right)-\sum_{k=1}^{i-1} I_{n}\left(w_{(k)}\right)} .
$$

Here, $I_{n}\left(w_{(i)}\right)$ stands for the $i^{\text {th }}$ largest periodogram ordinate. Under the null hypothesis the probability of $V_{i}>c_{\alpha}$ is approximated as $P\left(V_{i}>c_{\alpha}\right) \cong m\left(1-c_{\alpha}\right)^{m-1}$ where $m$ is the integer part of $n / 2$. Therefore, if $V_{i}>c_{\alpha}$ then the null hypothesis $H_{0}: A=B=0$ is rejected and conclude that there exist a priodic component at the $i^{\text {th }}$ frequency (or at the corresponding period). From the approximation, the critical values are calculated by setting $P\left(V_{i}>c_{\alpha}\right)=\alpha\left(c_{\alpha}=1-(\alpha / m)^{1 /(m-1)}\right)$.

\section{Findings}

We used the export and import data set for the period 1980:01-2017:12. In order to look at the Customs Union effect we separated the data in two parts 1980:01-1995:12 and 1996:01-2017:12. For these three data set, we check the stationarity, co-integration and periodicities.

\subsection{Exports and Imports in the Whole Period: 1980:01-2017:12}

Figure 1 shows the common time series graphs of import and export series for the period 1980:01-1995:12. Both series exhibit an increasing trend. The time series graphs of logarithmic transformation of export and import ( $x=\log (\exp o r t), y=\log ($ import $)$ ) data are presented by Figure 1 and standard time series plots are given in Figure 2. 
Figure 1. The Common Graph of Import and Export Series, 1980:01-2017:12

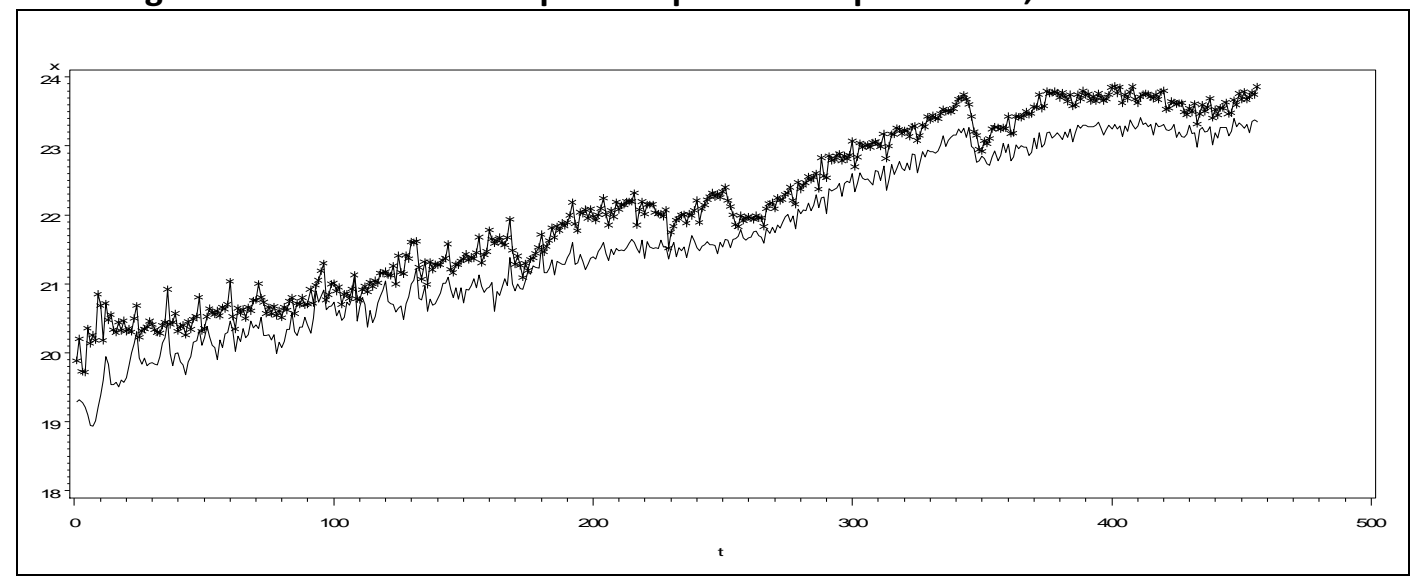

(*Import, solid Export)

Figure 2: Time Series Graphs of International Trade Data, 1980:01-2017:12

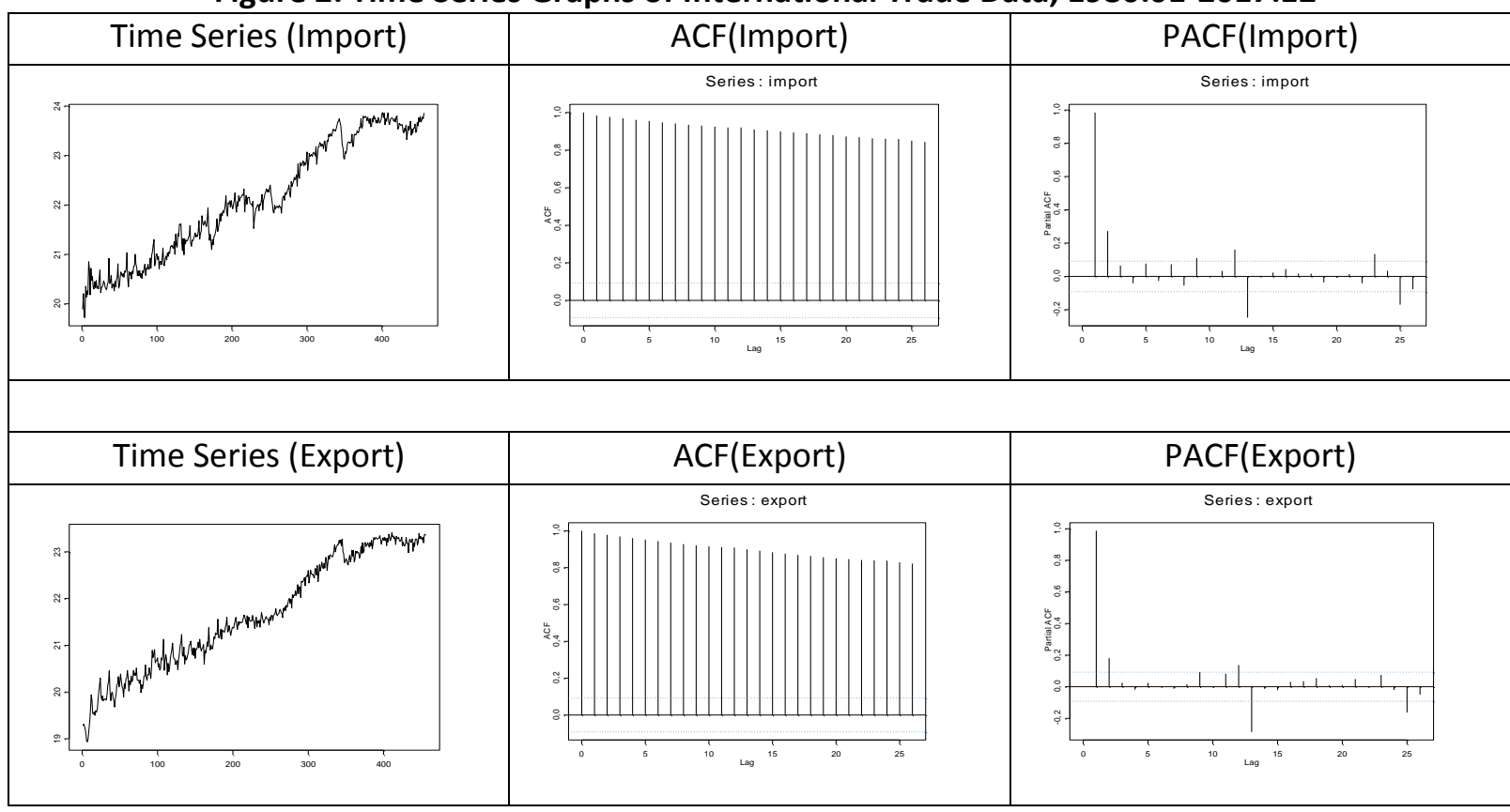

When Figure 2 is analysed in detail, an increasing trend and a constant autocorrelations are observed in both series. This situation highlights the existence of nonstationary series. As it is known, the series containing $A R$ and $A R$ components may not be stationary. Based on the smallest AIC values, the following models for the export and import series seem to be appopriate:

$$
\begin{aligned}
& X_{t}=\alpha_{0}+\alpha_{1} X_{t-1}+\alpha_{2} X_{t-2}+\alpha_{12} X_{t-12}+\alpha_{13} X_{t-13}+e_{t}, t=1,2, \ldots, n \\
& Y_{t}=\beta_{0}+\beta_{1} Y_{t-1}+\beta_{2} Y_{t-2}+\beta_{12} Y_{t-12}+\beta_{13} Y_{t-13}+e_{t}, t=1,2, \ldots, n
\end{aligned}
$$

In order to determine the degree $\mathrm{p}$ of each model, the AIC statistics and corresponding $\sigma^{2}$ estimates are presented by Table 1.

Table 1: AIC Statistics and Variance Estimates

\begin{tabular}{|c|c|c|c|c|c|c|}
\hline \multicolumn{7}{|c|}{ Import } \\
\hline$P$ & 1 & 2 & 12 & 13 & $(1,2,12,13)$ & $(1,12,13)$ \\
\hline
\end{tabular}




\begin{tabular}{|c|c|l|l|l|l|l|}
\hline AIC & -370.055 & -444.254 & -504.05 & -563.704 & -565.126 & -519.927 \\
\hline$\hat{\sigma}_{n}^{2}$ & 0.025865 & 0.021957 & 0.018848 & 0.016502 & 0.016771 & 0.018559 \\
\hline \multicolumn{7}{|c|}{ Export } \\
\hline $\mathrm{P}$ & 1 & 2 & 12 & 13 & $(1,2,12,13)$ & $(1,12,13)$ \\
\hline AIC & -476.618 & -535.377 & -571.636 & -704.631 & -718.893 & -673.587 \\
\hline$\hat{\sigma}_{n}^{2}$ & 0.020497 & 0.017980 & 0.016252 & 0.012115 & 0.011971 & 0.013250 \\
\hline
\end{tabular}

Based on these models, sum of the values of the OLS estimators are close to 1 .

For the import data $\hat{\beta}_{1}+\hat{\beta}_{2}+\hat{\beta}_{12}+\hat{\beta}_{13}=0.61637+0.28466+0.46719-0.36822=1$

For the export data $\hat{\alpha}_{1}+\hat{\alpha}_{2}+\hat{\alpha}_{12}+\hat{\alpha}_{13}=0.66448+0.24275+0.53953-0.44676=1$

These results indicate that both series do not stationary. Usual unit root test are applied these series and the values of $\hat{\tau}_{\mu}$ are given in below.

Import Series $\left(Y_{t}\right) \hat{\tau}_{\mu}=-0.562965$, First differenced import series $\left(\nabla Y_{t}\right) \hat{\tau}_{\mu}=-6.974595$

Export series $\left(X_{t}\right) \quad \hat{\tau}_{\mu}=-1.365390$ First differenced export series $\left(\nabla Y_{t}\right) \hat{\tau}_{\mu}=-5.886059$

The critical values are -3.444890 for $\% 1,-2.867845$ for $\% 5$ and -2.570192 for $\% 10$.

Therefore both export and import series are integrated of order $1(I(1))$. We also apply the periodogram based unit root test to check the order of integration for both series, export and import. The resulst are given below in Table 2 .

Table 2: Periodogram Based Unit Root Test

\begin{tabular}{|l|c|c|c|c|}
\hline & \multicolumn{2}{|c|}{ level } & \multicolumn{2}{c|}{ First Difference } \\
\hline Variable & $I_{n}\left(w_{1}\right)$ & $t_{n}\left(w_{1}\right)$ & $I_{n}\left(w_{1}\right)$ & $t_{n}\left(w_{1}\right)$ \\
\hline Export & 413.247 & 6.55394 & 0.00010 & 0.000001607 \\
\hline Import & 417.814 & 4.72985 & 0.00032 & 0.000003671 \\
\hline
\end{tabular}

Critical Values: $P\left(T_{n}\left(w_{1}\right)<0.03485\right)=0.01, P\left(T_{n}\left(w_{1}\right)<0.1784\right)=0.05$ and $P\left(T_{n}\left(w_{1}\right)<0.3681\right)=0.10$

Based on these results, both series are integrated of order 1 . Since, both series are integrated at the same order, we look at a possible co-integration relationship between export and import series. First we apply Engle and Granger method and consider the following regression equation;

$$
Y_{t}=\beta_{0}+\beta_{1} X_{t}+e_{t}, t=1,2, \ldots, n
$$

and look at the residual series is stationary or not. The prediction equation is observed as

$$
\hat{Y}_{t}=1.14750+0.96813 X_{t}, t=1,2, \ldots, n \text {. }
$$

Let $\hat{e}_{t}$ denote the residual series obtained from the prediction equation given above. In order to check the stationarity of the residual series we apply ADF test. We observe that $\hat{\tau}_{E-G}=-6.152758$ and since $\hat{\tau}_{E-G}=-6.152758<-3.17$, the residual series $\hat{e}_{t}$ is stationary and import and export series 
are co-integrated according to Engle and Granger (1987) approach (critical values are obtained from Wei, 2006, 437). At $\% 5$ significance level, the critical value is -3.17 , the series are co-integrated at $\% 5$ level of significance. The series are also co-integrated at \%1 level of significance since the critical value at $1 \%$ is -3.73 . We conclude that these series are co-integrated with the estimated cointegration vector $\hat{\beta}_{E G}=(-0.96813,1)^{\prime}$.

We also apply the periodogram based co-integration method to the export and import series. For this method we consider a regression $y_{k}=\alpha+\beta x_{k}+\eta_{k}, k=1,2, \ldots,[n / 2]$ and we observe that $\hat{\beta}_{p, n}=1.00469$.

For the whole sample, the OLS estimate of $\beta$ is obtained as $\hat{\beta}_{p, n}=1.00469$. In order to test whether import and export series are co-integrated $Z_{t}=Y_{t}-\hat{\beta}_{P, n} X_{t}$ series are considered. If these series are stationary, then import and export series are co-integrated. For this, $\nabla Z_{t}$ series are regressed on $Z_{t-1}$ series $\left(\nabla Z_{t}=\alpha_{0}+\alpha_{1} Z_{t-1}+u_{t}, t=1,2, \ldots, n\right)$ and the significance of coefficient of $Z_{t-1}$ is tested by using a t statistics. If the hypothesis $H_{0}: \alpha_{1}=0$ is rejected, import and export series are co-integrated. However, the distribution of $t$ statistics here is not standard $t$. The critical values of $t$ statistics are given by Akdi et al. (2006). At $5 \%$ significance level, it is -3.43564 and for $\% 10$ is -3.12867$)$. If the calculated $t$ statistics is less than the critical value, two series are cointegrated. For our model, the value of $t$ statistics for the coefficient of $Z_{t-1}$ is $\hat{\tau}_{a}=-8.80$ and $\hat{\tau}_{a}=-8.80<-3.43564=c_{0.05}$. Thus, both series are co-integrated. Therefore, the estimated cointegration vector is ${\underset{\sim}{\beta}}_{p}=(-1.00469,1)^{\prime}$.

Since both series are nonstationary, in order to search hidden periodicities in the data, we use the first differences. Based on the first differences, the largest 5 periodogram values and related values of $V_{i}$ statistics are given below in Table 3.

Table 3: The Largest 5 Periodogram Values, Related $V_{i}$ Values and Periods

\begin{tabular}{|c|c|c|c|c|c|c|}
\hline & \multicolumn{3}{|c|}{$\nabla Y_{t}$} & \multicolumn{3}{c|}{$\nabla X_{t}$} \\
\hline & $I_{n}\left(w_{(i)}\right)$ & Period & $V_{i}$ & $I_{n}\left(w_{(i)}\right)$ & Period & $V_{i}$ \\
\hline & 0.668433 & $\mathbf{2 . 9 9 3}$ & 0.0721 & 0.812546 & $\mathbf{2 . 9 9 3}$ & 0.0964 \\
\hline & 0.614717 & $\mathbf{2 . 3 9 5}$ & 0.0715 & 0.799077 & $\mathbf{3 . 9 9 1}$ & 0.0733 \\
\hline & 0.582975 & $\mathbf{5 . 9 8 7}$ & 0.0730 & 0.639370 & $\mathbf{5 . 9 8 7}$ & 0.0633 \\
\hline & 0.518290 & $\mathbf{3 . 9 9 1}$ & 0.0700 & 0.555858 & $\mathbf{2 . 3 9 5}$ & 0.0588 \\
\hline & 0.409973 & $\mathbf{2 . 3 2 1}$ & 0.0595 & 0.520370 & $\mathbf{2 . 4 0 7}$ & 0.0584 \\
\hline Total & $\mathbf{9 . 2 6 8 2 7 7 1 5}$ & & & $\mathbf{1 1 . 7 0 7 4 8 0 2}$ & & \\
\hline
\end{tabular}


We have $n=456$ observations and therefore we have $m=227$ to calculate the critical values ( 455 observations for the first differenced series). From the equation $P\left(V>c_{\alpha}\right)=m\left(1-c_{\alpha}\right)^{m-1}$ we calculate the critical values by using $c_{\alpha}=1-(\alpha / m)^{1 /(m-1)}$ equation.

Table 4: The Critical Values of $V_{i}$

\begin{tabular}{|c|c|c|c|c|c|}
\hline$\alpha$ & $\mathbf{0 . 0 1}$ & $\mathbf{0 . 0 2}$ & $\mathbf{0 . 0 3}$ & $\mathbf{0 . 0 4}$ & $\mathbf{0 . 0 5}$ \\
\hline$c_{\alpha}$ & 0.0434 & 0.0405 & 0.0387 & 0.0375 & 0.0366 \\
\hline$\alpha$ & $\mathbf{0 . 0 6}$ & $\mathbf{0 . 0 7}$ & $\mathbf{0 . 0 8}$ & $\mathbf{0 . 0 9}$ & $\mathbf{0 . 1 0}$ \\
\hline$c_{\alpha}$ & 0.0358 & 0.0351 & 0.0346 & 0.0341 & 0.0336 \\
\hline
\end{tabular}

According to Tables 3 and 4, there are 2, 3, 4 and 6 month periods for the first differenced series at $5 \%$ significance level in both export and import series.

\subsection{Exports and Imports in the Periods 1980:01-1995:12 and 1996:01-2017:12}

The same procedure is repeated for the periods, 1980:01-1995:12 and 1996:01-2017:12 to look at the effects of Customs Union agreement. For the stationarity of series, the same analyses have been repeated and summarized the results below in Table 5a and 5b. We observe the series are integrated of order one for both periods.

Table 5a: ADF test Statistics

\begin{tabular}{|l|l|l|l|l|}
\hline & \multicolumn{2}{|c|}{$1980: 01-1995: 12$} & \multicolumn{2}{c|}{$1996: 01-2017: 12$} \\
\hline Variable & Level & First Difference & level & First Difference \\
\hline Export & -1.315697 & -5.275242 & -0.989604 & -5.044932 \\
\hline Import & 0.565682 & -5.133218 & -0.933441 & -4.092759 \\
\hline
\end{tabular}

Critical values: $\quad$ First period (-3.446994 for \%1, -2.877544 for $\% 5$ and -2.575381 for $10 \%)$ Second period ( -3.446302 for $1 \%,-2.872857$ for $\% 5$ and -2.572875 for $10 \%$ )

Table 5b: Periodogram based Unit Root test Statistics

\begin{tabular}{|l|c|c|c|c|c|c|}
\hline & \multicolumn{3}{|c|}{$1980: 01-1995: 12$} & \multicolumn{3}{c|}{$1996: 01-2017: 12$} \\
\hline Variable & $I_{n}\left(w_{1}\right)$ & $\hat{\sigma}_{n}^{2}$ & $t_{n}\left(w_{1}\right)$ & $I_{n}\left(w_{1}\right)$ & $\hat{\sigma}_{n}^{2}$ & $t_{n}\left(w_{1}\right)$ \\
\hline Export & 27.0190 & 0.030335 & 0.95377 & 0.00597 & 0.017755 & 0.000364 \\
\hline Import & 25.5689 & 0.038386 & 0.71328 & 0.00532 & 0.025444 & 0.000226 \\
\hline
\end{tabular}

Critical Values: $P\left(T_{n}\left(w_{1}\right)<0.03485\right)=0.01, P\left(T_{n}\left(w_{1}\right)<0.1784\right)=0.05$ and $P\left(T_{n}\left(w_{1}\right)<0.3681\right)=0.10$

Table 6: Co-integration

\begin{tabular}{|c|c|c|c|c|}
\hline & \multicolumn{2}{|l|}{ Engle-Granger } & \multicolumn{2}{|l|}{ Periodogram } \\
\hline Period & $\hat{\beta}_{E G}=\left(-a_{21} / a_{11}, 1\right)^{\prime}$ & $\hat{\tau}_{E G}$ & $\hat{\beta}_{p}=\left(-a_{21} / a_{11}, 1\right)^{\prime}$ & $\hat{\tau}_{a}$ \\
\hline 1980:01-1995:12 & ${\underset{\sim}{\hat{\beta}}}_{E G}=(-0.79213,1)^{\prime}$ & -6.06 & $\hat{\beta}_{\sim}=(-0.89881,1)^{\prime}$ & -6.01 \\
\hline 1996:01-2017:12 & $\hat{\beta}_{E G}=(-0.95432,1)^{\prime}$ & -7.07 & $\hat{\beta}_{p}=(-0.98628,1)^{\prime}$ & -7.04 \\
\hline Critical values & \multicolumn{2}{|c|}{-3.73 for $\% 1$ and -3.17 for $\% 5$} & \multicolumn{2}{|c|}{-3.43564 for $\% 5$ and -3.12867 for $\% 10$} \\
\hline
\end{tabular}


Table 7a: Periodicities for the Period 1980:01-1995:12

\begin{tabular}{|c|c|c|c|l|c|}
\hline \multicolumn{3}{|c|}{$\nabla X_{t}$} & \multicolumn{3}{c|}{$\nabla Y_{t}$} \\
\hline$I_{n}\left(w_{(i)}\right)$ & Period & $V_{i}$ & $I_{n}\left(w_{(i)}\right)$ & \multicolumn{1}{|c|}{ Period } & $V_{i}$ \\
\hline 0.576840 & $11.938^{* * *}$ & 0.1009 & 0.555766 & $2.418^{*}$ & 0.0752 \\
\hline 0.513926 & $2.388^{* * *}$ & 0.0999 & 0.473243 & 2.984 & 0.0692 \\
\hline 0.511538 & $2.984^{* * *}$ & 0.1105 & 0.447342 & 3.979 & 0.0703 \\
\hline 0.467051 & $2.329^{* * *}$ & 0.1135 & 0.357402 & 5.969 & 0.0604 \\
\hline 0.333845 & $3.979^{* *}$ & 0.0915 & 0.342813 & 2.329 & 0.0617 \\
\hline$\sum_{i=1}^{m} I_{n}\left(w_{(i)}\right)=5.71898798$ & $\sum_{i=1}^{m} I_{n}\left(w_{(i)}\right)=7.39124681$ \\
\hline
\end{tabular}

Critical values: 0.0928 for $\% 1,0.0772$ for $\% 5$ and 0.0703 for $\% 10$

$\left({ }^{*}\right)$ : significant at $10 \%,\left({ }^{* *}\right)$ : significant at $5 \%$, and $\left({ }^{* *}\right)$ : significant at $1 \%$

Table 7b: Periodicities for the Period 1996:01-2017:12

\begin{tabular}{|c|c|c|c|c|c|}
\hline \multicolumn{3}{|c|}{$\nabla X_{t}$} & \multicolumn{3}{c|}{$\nabla Y_{t}$} \\
\hline$I_{n}\left(w_{(i)}\right)$ & Period & $V_{i}$ & $I_{n}\left(w_{(i)}\right)$ & Period & $V_{i}$ \\
\hline 0.290810 & $2.327^{* * *}$ & 0.0845 & 0.369102 & $2.989^{* * *}$ & 0.0877 \\
\hline 0.247329 & $2.989^{* * *}$ & 0.0785 & 0.356039 & $2.327^{* * *}$ & 0.0927 \\
\hline 0.223685 & $5.977^{* * *}$ & 0.0770 & 0.332026 & $3.985^{* * *}$ & 0.0953 \\
\hline 0.222128 & $2.391^{* * *}$ & 0.0828 & 0.322886 & $2.391^{* * *}$ & 0.1024 \\
\hline 0.218944 & $2.071^{* * *}$ & 0.0890 & 0.257742 & $2.890^{* * *}$ & 0.0911 \\
\hline$\sum_{i=1}^{m} I_{n}\left(w_{(i)}\right)=3.44306877$ & $\sum_{i=1}^{m} I_{n}\left(w_{(i)}\right)=4.20975399$ \\
\hline
\end{tabular}

Critical values: 0.0703 for $\% 1,0.0587$ for $\% 5$ and 0.0537 for $\% 10$

$\left({ }^{*}\right)$ : significant at $10 \%,\left({ }^{* *}\right)$ : significant at $5 \%$, and $\left({ }^{* *}\right)$ : significant at $1 \%$

In a summary, for whole sample 2,3,4 and 6 month-periods are significant at $1 \%$ level for both import and export series.

For the first sample (1980:01-1995:12) while we observe 2,3 and 12 month-periods are significant at $1 \%$ level and 4 month- period is significant at $5 \%$ level for the export series, we observe 12 monthperiod is significant only at $10 \%$ level.

For the second period (1996:01-2017:12), the 2,3 and 6 month-periods are significant at $1 \%$ level for the export series and 2, 3, 4 and 6 month-periods are significant at $1 \%$ level.

\section{Concluding Remarks}

The EU is the most important trade partner of Turkey and the trade relations between EU and Turkey has improved with the introduction of CU after 1996. This study, different from the previous studies, presents evidence on the hidden periodicity in international trade and impact of CU on the periodicity. For the whole period between 1980:1 and 2017:1, an increasing trend in constant autocorrelations are observed both in export and import series which stand as an evidence for nonstationary series. This observation is verified with ADF and periodogram based unit root tests. The first differences of make the series stationary that leads to conclusion that both series are 
integrated of order 1 . In order to search for possibility of co-integration relationship in the data, both Engle-Granger approach and periodogram based co-integration method are employed. The results show that both series are co-integrated and converge towards long-run equilibrium. When the hidden periodicity is investigated, it is found that there are 2, 3, 4 and 6 month periods for the first differenced export and import series at $5 \%$ significance level. The same procedure is repeated for pre and post-CU periods.

Both series are again non-stationary as expected and again first differences become stationary. However, there are two interesting findings when two periods are compared. First is the magnitude of the co-integrating vector. For both Engle-Granger approach and periodogram based co-integration method, the magnitude of the cointegrating vector is lower in pre-CU period. This is an important evidence in favour of $\mathrm{CU}$, meaning that with the introduction of $\mathrm{CU}$ the long-run equilibrium relation is reached relatively in a shorter period of time. Therefore, the most important policy implication of this result is that Turkey seemed to benefit from CU. The second result is related with the comparison of periodicity in two periods. It is shown that with the introduction of $\mathrm{CU}$, the periodicity in the data lessens that might be a disadvantage as the periodicity of the shocks in international trade becomes more frequent. The possible explanation for such a behaviour of data is the transfer of business cycles impacts from EU to Turkey. There is an empirical evidence for such a behaviour in the literature (Bergman, 2004 and Artis et al., 2008). In this context, which factor outweighs the other needs further investigation. However, what is evident from the analysis that modernisation of $\mathrm{CU}$ will have a potential to outweigh the second behaviour in the data. This may provide possible welfare gains in the long-run for Turkey. The analysis will also provide considerable insights for the policy making throughout the current Brexit talks. As a point of departure for a further study concerning periodicity in international trade, this issue needs further studies on the business cycles of EU and its relations with the other trading partners including UK which is outside the scope this study.

\section{References}

Akdi, Y. (1995) Periodogram Analysis for Unit Roots, Ph.D. Dissertation, North Carolina State University, USA.

Akdi, Y. and Dickey D.A. (1998) Periodograms of Unit Root Time Series: Distributions and Tests, Communications in Statistics, Theory and Methods 27, 69-87. https://doi.org/10.1080/03610929808832651

Akdi, Y., Berument H. and Cilasun S.M. (2006) The relationship between different price indices: Evidence from Turkey, Physica A 360, 483-492. https://doi.org/10.1016/j.physa.2005.05.037 
Antonucci D. and Manzocchi, S. (2006) Does Turkey have a special trade relation with the EU? A gravity model approach, Economic Systems. 30, 157-69. https://doi.org/10.1016/j.ecosys.2005.10.003

Artis, M.J., Fidrmuc, J. and Scharler, J. (2008)The transmission of business cycles: Implications for EMU enlargement, Economics of Transition 16, 559-582. https://doi.org/10.1111/j.14680351.2008.00325.x

Bergman, U.M. (2004) How similar are European business cycles? EPRU Working Paper Series, No. 2004-13.

Bilici, Ö., Erdil, E. and Yetkiner, I.H. (2011) The determinants of Turkey's trade flows: A gravity model approach, Actual Problems of Economics. 118, 265-79.

Charilaos, M. (2017) Understanding the EU-Turkey sectoral trade flows during 1990-2016: A trade gravity approach, FEUTURE online paper No.8, http://www.feuture.unikoeln.de/sites/feuture/user upload/D3.2 Online Paper Nr 8 neu.pdf (accessed 31 January 2018).

Dickey, D.A. and Fuller W.A. (1979) Distribution of estimates for autoregressive time series with a unit root, J. Amer. Statist. Assoc. 74, 427-431. https://doi.org/10.1080/01621459.1979.10482531

Ekmen, S. (2012) Turkey's Export Competitiveness in the EU-15 Market. Unpublished Ph.D. Thesis, METU, Ankara, Turkey.

Engle, R.F. and Granger C.W.J. (1987) Co-integration and error correction: representation, estimation and testing, Econometrica 55, 251-276. https://doi.org/10.2307/1913236

Frankel, J. (1997) Regional Trading Blocs in the World Economic System, Institute for International Economics, Washington D.C.

Fuller W.A. (1996) Introduction to Statistical Time Series, Second Ed. Wiley, New York. https://doi.org/10.1002/9780470316917

Krueger, A. (1999) Trade creation and trade diversion under NAFTA. NBER Working Paper 7429. https://doi.org/10.3386/w7429

Lejour, A. M. and de Mooij R. A. (2005) Turkish Delight: Does Turkey's accession to the EU bring economic benefits? Kyklos 58, 87-120. https://doi.org/10.1111/j.0023-5962.2005.00279.x

Pöyhönen, P. (1963) A tentative model for the volume of trade between countries, Weltwirtschaftliches Archiv. 90, 93-100.

Sologa, I. and Winters, L., A. (1999) How has regionalism in the 1990s affected trade? World Bank Policy Research Working Paper, No. 2156. https://doi.org/10.1596/1813-9450-2156 
Tinbergen, J. (1962) Shaping the World Economy: Suggestions for an International Economic Policy. New York: The Twentieth Century Fund.

Wei W.W. S. (2006) Time Series Analysis: Univariate and Multivariate Methods, Second Ed. Pearson Education, Inc., Boston. 